УДК. 621.38; 536.5

I. В. Мірошниченко, О. О. Гагарін, О. В. Баранюк

\title{
ОСНОВНІ ПАРАМЕТРИ АДАПТІВНИХ СИСТЕМ ОБРОБКИ ЕКСПЕРИМЕНТАЛЬНИХ ДАНИХ
}

Показано, що для автоматизованих систем обробки експериментальних даних необхідно в алгоритмі закладати можливості адаптації по швидкості обробки, підвищенню точності, можливості комплексирования вимірювань. Користувачам повинна бути надана можливість зміни взаємодії з системою в залежності як від параметрів вхідних даних, що підлягають обробці за фіксованими або змінними програмами, так і від стану бази даних по конкретній наочній області.

Ключеві слова: інформатика, система обробки експериментальних даних, інформаційно-вимірювальна система стаціонарні гаусові випадкові процесі

\section{Вступ}

По відношенню до технічних систем (ТC), якими називатимемо сукупність динамічно зв'язаних штучних компонентів, утворюючих цілісну внутрішню структуру і володіючих зовнішньою цілеспрямованістю, термін "адаптація" вперше з'явився в теорії автоматичного управління, потім в радіотехніці і зв'язку, в гідроакустиці і інших областях науки і техніки. Під адаптивними ТС (АДТС) розумілися такі, для яких було зручне застосовувати термін "адаптація", причому сам термін не вимагав додаткових роз'яснень. Дещо пізніше за його сталь визначати через не підлягаючі уточненню терміни типу "навчання", "самонавчання", "ефективність" і т. д., що не особливо сприяло проясненню ситуації [1].

В широкому значенні адаптивність ТС - це здатність системи модифікувати себе або зовнішне середовище при зміні умов функціонування з метою компенсації (хоча б часткової) втрати ефективності функціонування.

3 технічної точки зору адаптація є однією із способів використовування автоматизованої техніки, що приводять до появи якісно нової властивості у функціонуванні ТС. В техніці адаптація - це вищий ступінь автоматизації ТС, що характеризується не тільки наявністю зворотних зв'язків, але і обов'язковою наявністю у складі ТС пристроїв вимі- 
рювання і аналізу результатів цих вимірювань, наділяючи властивістю пам'яті і володіючих здатністю ухвалювати деякі рішення на основі аналітичних і формальних логічних висновків.

3 системної точки зору адаптація є процесом безперервної оптимізації, тому будь-яка АДТС повинна, принаймні, протягом деякого часу, підтримувати свою оптимальність.

3 математичної точки зору АДТС повинні вирішувати задачі стохастичної екстраполяції, тобто прогнозувати якість свого фрункціонування і підтримувати його на деякому заданому рівні (наприклад, верхньому) протягом наперед певного інтервалу часу.

Загальний принцип побудови адаптивних систем заснований на вимірюванні, тобто отриманні оцінок, відомих (або визначуваних в процесі роботи АДТС інформативних параметрів, запам'ятовуванні цих оцінок і введення їх у вибраний функціонал обробки. При цьому практично завжди залишається невиясненою оптимальність всієї процедури в цілому, оскільки вид оцінки вибирається з позицій теорї̈ вилірювань, що припускає отримання оцінок параметрів з деякою погрішністю, а фрункціонал обробки - з позицій теорї перевірки гіпотез, що припускає наявність всієї (або достатньо повної) інформації про об'єкт [2].

Розуміючи під оптимізацією досягнення як найкращого результату фрункціонування ТС з безлічі можливих варіантів ії побудови, у складі системи обробки експериментальних даних (СОЕД) на рівні системного аналізу необхідно розглянути вимірювальний блок (далі званий інформаційно-вимірювальною системою - IBC або вимірювально-обчислювальним комплексом - IBК) та блок аналізу і ухвалення рішень [3].

3 теоретичної точки зору інфрормаційно-вимірювальний підхід гарантуе вимірність різних множин. Основою побудови теорії вимірювань повинне бути вивчення топологічних властивостей множин, причому міра топології вимірних множин повинна дозволити ввести амплітудний, просторовий і тимчасовий заходи процесу і прийти до поняття інформаційної продуктивності ознак, властивості яких відображаються у вигляді результатів вилірювань[4].

Постановка задачі зводиться до розробки класифікації параметрів адаптації у системах обробки експериментальних даних та інформаційно-вимірювальних системах(IBC), розробки загальних для всіх 
систем, їх вузлів і блоків, а також середовищ розповсюдження сигналів (носіїв інформації) методології вимірювання інформативних параметрів, отримання оцінок цих параметрів і оптилально погоджувати їх

Основний зміст. IBC (синонім - IBК) - багатоканальний $i$ (або) багатоббункиіональний технічний пристрій, призначений для вимірювань і є сукупністю засобів вимірювань (ЗВ) - вимірювальних приладів (ВП), первинних і вторинних вимірювальних перетворювачів (ПВП і ВВП), з'єднаних загальним алгоритмом фрункціонування і призначену для отримання даних про стани об'єкту шляхом деяких перетворень безлічі фрізичних величин, розподілених в часі і в просторі

Якщо результатом перетворень $є$ іменоване число $[\mathrm{N}]=n \Delta x$, яке має розмірність $x$ [1] і отримане як результат рахунку $n$ одиниць вимірювання $\Delta x$, те таке перетворення називається вимірюванням; якщо логічні вислови типу “більше, рівно, менше" - то контролем. Звідси слідують відмінності між IBC і системами автоматизованого контролю (тобто з участю людини-оператора) або автоматичного контролю (без участі оператора), часто що позначаються абревіатурою - САК.

Систели обробки експерилентальних даних (СОЕД), виконуючі всі основні фрункції IBC, мають додаткову нагоду дії на об'єкт вимірювань з метою наближення до $E X T R\left\{\begin{array}{c}M A X \\ M I N\end{array}\right\}$ цільової функції експерименту (погрішності, надійності, витрат ресурсів і т. д.).

В таких термінах задача оптимізації АДТС зводиться до послідовного рішення для обох блоків ТС трьох основних етапів:

- отриманню аналітичної залежності для цільових функцій (наприклад, для погрішностей вимірювань, що є визначальним показником якості для IBC і СОЕД);

- знаходженню математичних співвідношень для цілком певних задач оптимізації;

- ухвалення рішення по одному з вибраних (або спеціально розроблених) критеріӥв.

Для оцінки ефрективності будь-кого ТС необхідно передбачити сумісний аналіз ефректу від застосування ТС при виконанні сукупності умов, що реалізовують прийняті принципи і витрат на його досягнення. 
При цьому використовуються технічні, економічні і техніко-економічні критерії ефрективності ТС .

Технічні критерії (їх досить багато) звичайно відображають технічний рівень ТС (тобто “досконалість” з погляду розробників) або ступінь придатності ТС для вирішення поставлених задач. Проте така оцінка носить односторонній характер і є в більшості випадків недостатньою, за винятком тих, випадків, коли зняті економічні обмеження (наприклад, у військовій області, в космічних дослідженнях).

Економічні критеріӥ (звичайно вартості витрат ресурсів), будучи більш загальнили і універсальнили, не відображають, в більшості випадків, технічної досконалості (знову ж таки, з погляду розробників) $i$ диналіки роботи ТС.

Техніко-еконолічні (колплексні) критеріӥ більш переважні, тому завжди робляться спроби формування таких критеріїв оцінки едективності ТС, що представляють, наприклад для IBC, собою мінімум погрішності при обмеженнях на ресурси.

Для більшості ТС можливі чотири види адаптаціӥ:

- зовнішньо-зовнішня, коли ТС реагує на зовнішні зміни модифікацією свого оточення (виключення, у тому числі і знищення, зовнішніх джерел перешкод; екранування, перенесення самої ТС в інше місце;

- зовнішньо-внутрішня, коли ТС реагує на зовнішні зміни модифікацією самої себе (найтиповішим прикладом є зміна структури оптимального приймача сигналів при зміні характеру перешкод), включаючи самоліквідацію;

- внутрішньо-зовнішня, при якій ТС на внутрішні зміни реагує модифікацією свого оточення (включення зовнішніх джерел живлення при енергетичній адаптації, включення зовнішнього резерву при відмовах, а також прийоми дублювання і резервування і т.д.;

- внутрішньо-внутрішня, коли ТС у відповідь на внутрішні зміни модифікує сама себе (наприклад, адаптивні приймачі з внутрішнім контуром адаптації).

Існування різних шляхів і методів зменшення погрішностей СОЕД і IBC викликано деякою відмінністю в підході до їх аналізу в теоріях вимірювань, надійності, перешкодозахисних (перешкодостійкості) i інших суміжних галузях науки і техніки. Методи підвищення точності 
систем можна розбити на три основні групи, включаючи ті або інші принципи адаптації.

1. Усунення салих джерел погрішностей або їх придушення в місці виникнення. Типовими прикладами можуть служити методи придушення індустріальних перешкод усередині цих джерел (екранування); зменшення внутрішніх шумів блоків і вузлів електронної апаратури при переході на досконалішу (або принципово іншу) елементну базу; ослаблення взаємного впливу між каналами (тимчасове, просторове i інші види розділення сигналів в каналах IBC); підвищення перешкодостійкості систем за рахунок переходу каналів зв'язку на складні і шумоподібні сигнали; перехід на нові, нетрадиційні діапазони передачі і обробки сигналів (міліметрові хвилі, оптичні лініі), де рівень перешкод різко зменшується; термостабілізація і термоізоляція (зменшення тепловиділення); зменшення числа контактів застосуванням інтегральної технології; стабілізація джерел живлення і т.д.

2. Ослаблення дї джерел похибок в тих місцях системи, де дія їх максимально. Сюди можна віднести застосування просторово-часової обробки сигналів в приймальних частинах IBC для зменшення впливу перешкод; застосування принципів компенсації, інваріантності і комплексірування вимірювань для зменшення апаратурної погрішності; резервування апаратури і вбудований контроль для підвищення надійності, в тон числі і метрологічної; застосування принципу зворотного зв'язку (33) у всій IBC або її частинах в різних видах (негативної, позитивної, виборчої, невиборчої і т.д.) для зменшення погрішності вимірювань за рахунок зменшення внутрішніх нестабільностей, зменшення лінійних і нелінійних спотворень, придушення деяких видів перешкод і т.д.; термостатировання, екранування і інші види захисту від електричних, магнітних, акустичних i інших полів; тренування апаратури для виявлення відмов і т.д.

3. Колбіновані летоди, що дозволяють усунути одні джерела похибок і ослабити дію деяких інших джерел.

Одним з основних комбінованих методів дії є перехід від аналогової до цифрової обробки електричних сигналів, при якій усувається погрішність від не лінійності, зменшується вплив нестабільності тракту передачі. Завдяки використовуванню інтегральних схем 3 великим рівнем інтеграції двійкових цифрових елементів з'являється можливість реалізації більш перешкодостійких алгоритмів (адаптивних, 
просторово-часової обробки, стохастичних ітераційних і т.д.) обробки і розширяються можливості резервування апаратури за рахунок застосування типових елементів заміни (ТЕЗ).

Проте, разом із застосуванням ряду специфічних для цифрової обробки ефективних алгоритмів, що підвищують точність, з'являються нові джерела погрішностей, наприклад, погрішності від квантування i погрішності алгоритмів. Проте при цьому значно розширяється смуга частот каналів зв'язку в IBC, що може усилити вплив інших погрішностей, наприклад, від кінцевої швидкості виконання операцій на ЕОМ. Але в більшості випадків аналого-цифрова обробка дозволяє підвищити “узагальнену точність“ (exactitude $-E T), E T=1 / \delta_{\Sigma}$ COEД і IBC [1].

Більшість об'єктів i сигналів при вимірюваннях параметрів траєкторій рухомих об'єктів в геоцентричній або геліоцентричній системах координат, сейсмології при локалізації наземних і підземних аномалій, радіолокації, гідрографії і гідроакустиці (ГА), фізичному моделюванні в авіації і космонавтиці (продування моделей в аеродинамічних трубах і т.п.) описується моделями вірогідності. В основі експериментальних досліджень в цих областях частіше за все лежить отримання оцінок характеристик вірогідності випадкових процесів, тобто статистичні вимірювання параметрів сигналів. Якщо інформація про досліджувані процеси обмежена, то виникає необхідність в адаптації (в широкому значенні), оскільки наперед практично неможливо оптилізувати структуру системи вимірювання і обробки сигналів, або, інакше кажучи, задати кількість і вид статистичних характеристик.

В інформаційно-вимірювальній техніці в даний час отримали розповсюдження, разом з традиційними, так звані структурні летоди підвищення точності [2], що використовують зовнішньо-внутрішню адаптацію.

При відомій структурі ТС і заданому алгоритмі обробки сигналів на етапі проектування IBC, приймаючи як визначальний показник якості погрішність вимірювання деякої характеристики, можна сформулювати вимоги до одного каналу IBC як до деякого засобу вимірювання (3B), що містить вимірювальний перетворювач (ВП), що проводить процедуру вимірювання і отримання результату вимірювання у вигляді іменованого числа одиниць вимірювання і спеціалізованої ЕОМ (аналогової або циф- 
рової), що виконує оптимальну, по вибраному або заданому критерію, обробку вихідних сигналів ІП на фоні перешкод.

Очевидно, що в IBC, на відміну від систем автоматичного управління (САУ), дійсні значення вхідного сигналу невідомі і, отже, не можуть бути оцінений так швидко, як виробляється “помилка розузгодження", що є основою для побудови САУ. В IВC принципово неможливо охопити зворотним зв'язком первинні ВП, що є основними джерелами нестабільності характеристик. Тому при проектуванні IBC i СОЕД різного рівня, у тому числі і адаптивних, необхідно враховувати наступні основні принципи:

- застосування інформаційних критеріїв ефективності адаптації;

- облік ступеня апріорної невизначеності умов роботи;

- використання статистичних методів вірогідності;

- використання формалізованого опису підсистем IBC.

Звичайно в таких випадках говорять про задачу статистичного синтезу з повною апріорною інформацією про вхідні сигнали, тобто коли густина вірогідності сигналу і перешкоди відома. Якщо ж густина вірогідності або деякі їх параметри невідома, то прийнято говорити про задачі статистичного синтезу в умовах апріорної невизначеності, причому слід завжди мати на увазі, що за відсутності апріорних відомостей про сигнали і перешкоди рішення задачі синтезу оптимальної системи неможливе у принципі. Проте на практиці завжди є деякі дані, засновані на попередньому досвіді, інтуїції або фізичному трактуванні задачі. 3 погляду інформатики фізичне трактування задачі і інтуїція відносяться до задач моделювання, ключовими, що є, а задача отримання апріорних даних - до задач формування баз знань по певному розділу науки і техніки, званому далі наочною областю або Problem area (PRAR) [3].

Зрештою можна говорити про розробку інформаційного (I3) і математичного (MЗ) забезпечення системи автоматизованого проектування (CAПР) у визначеній PRAR (наприклад, при вимірюваннях параметрів шорсткості в машинобудуванні, хвилястості поверхні в авіабудуванні і т. п.) і принципів адаптації алгоритмів роботи СОЕД і IBC. Вважаючи, що адаптивна IBC може пристосовуватися до зміни умов, модифікуючи свою структуру, кращі результати виходять при здійсненні направленого перебору варіантів структур, що спирається 
на певні знання, причому більш високоорганізовані системи спираються на велику базу знань.

Перший рівень самоорганізації будь-якої автоматизованої адаптивної СОЕД завжди орієнтований тільки на конкретну PRAR (наприклад, експертні системи), а алгоритм роботи системи представлений фіксованими програмами обробки. Саме програма обробки є основним інваріантом однорівневої адаптивної СОЕД, оскільки такі системи пристосовуються до поточних вхідних дій і поточного стану своєї бази знань.

Другий рівень самоорганізації АІВС повинен дозволяти змінювати програму основної обробки і деяку частину бази знань, часто звану умовно-постійною інформацією (класифікатори і тезауруси), при зміні умов функціонування. Основними інваріантами дворівневої адаптивної СОЕД є вже значення критерію ефективності, програми оптимізації (наприклад, для IBC - методи підвищення точності) і фіксовані набори модулів (I3, M3 і багатофункціональні елементи), з яких можуть збиратися AIBC різної архітектури. До цього типу дворівневих адаптивних СОЕД відноситься більшість сучасних адаптивних СОЕД [4].

В процесі проектування число ефективних ідей убуває приблизно по експоненціальному закону при одночасному не прогнозованому зростанні витрат, причому може виявитися, що за час проектування деяка ідея до моменту закінчення проектування і випробувань застаріє. Тому ідея оптимізації, в даному випадку по критерію “зменшення часу проектування", очевидна. Проте використовування методів оптимізації в "чистому вигляді" для задач проектування СОЕД утруднено через нечітку постановку задачі і майже завжди потрібна розробка специфічного для даної PRAR підходу, наприклад комплексірування вимірювань інформаційних параметрів сигналів.

Класична задача оптимізації полягає в знаходженні екстремального значення деякої функції $f\left(S_{1}, S_{2}, \ldots S_{K}\right)$ у визначеній прийнятим чином області, що задається нерівностями вигляду $\mathrm{G}$ або $\mathrm{G}\left(S_{1}, S_{2}, \ldots S_{K}\right) \leq 0[3]$.

Для вирішення цієї задачі застосовується багато методів: лінійне, нелінійне, динамічне, дискретне, опукле квадратичне (або стохастичне) програмування з різними підходами до обліку діючих обмежень (симплекс-метод Данцига; класичні методи варіаційного числення - 
рівняння Ейлера-Лагранжа; градієнтні методи - принцип оптимальності Р. Беллмана; принцип максимуму Понтрягина і інші методи). Вибір підходу залежить від вибору цільової функції і характеру обмежень, що припускає дослідження самої постановки на коректність.

Визначення коректності можна представити у вигляді, де $z$ рішення кількісної задачі за початковими даними, і є елементи метричних просторів і з відстанями між елементами i, при виконанні двох умов.

Улова I. Задача знаходження $z \in Z$ i називається коректною на парі метричних просторів і, якщо:

- визначено поняття рішення по $u$, тобто відомо, який результат і в якій формі бажано його отримати;

- є множину $u=\left\{u_{i}\right\}, i=\overline{1, N}$ таке, що для всякого $u \in U \in z \in Z$;

- $\operatorname{rank}(u)=z$, тобто рішення однозначно;

- задача стійка на просторі рішень $z=R(u)$, тобто виконуеться умова II.

Улова II . Задача знаходження $z=R(u)$ стійка на, якщо для будьякого числа існуе таке, що з витікае де $z_{1}=R\left(u_{1}\right) ; z_{2}=R\left(u_{2}\right) ; u_{1} u_{2} \in U ; z_{1} z_{2} \in Z$.

Порушення хоча б одного з пунктів цих умов свідчить про некоректність задачі.

Задачі оптимізації більшості СОЕД некоректні майже по всіх пунктах, тому для прикладних задач математиками (А.Н. Колмогоровим, А.Н. Тіхоновим, А.А. Самарою, М.І. Лаврентьевим, Г.И. Марчуком і ін.) були розроблені методи глобальної регуляризацї слабо коректних і некоректних задач: метод регуляризації А.Н. Тіхонова; методи регуляризації задач лінійного програмування на принципі інваріантності оптимальних рішень; методи регуляризації задач дискретного програмування, наприклад, метод "правильних "відсікань (алгоритм Гоморі) і т.д.

Умова регуляризації задач великої розмірності $m^{*} n$, де $m$ - число невідомих при $n$ обмеженнях, типовим зразком яких е задача оптимізації IBC в будь-кому PRAR, може бути сформульовано як умова застосування покрокової оптилізацї - субоптилізаиї, має універсальний характер. Субоптилізація є керівним правилом при оптимізацї різних 
багатоступінчатих іерархічних структур і тому часто породжує дію аналогічних прийомів: декомпозиції, іерархічності, модульної і т.д. Наприклад, в адаптивних СОЕД визначальним показником якості є погрішність вимірювання $\delta$, витрати на досягнення якої вступають в суперечність з цінністю, звичайно що зменшуеться з часом.

Узагальнивши вимоги до вибору показників якості $Q$ АДТС з урахуванням рекомендацій:

- по науковому обгрунтовуванню рішень і методів проектування, при яких вимоги надійності, у тому числі і метрологічної, е обов'язковими;

- про першорядне значення для більшості СОЕД інфрормаційної цінності;

- беручи до уваги те, що оптимальне рішення обов'язково повинне лежати в області компромісів, приходимо до необхідності уточнення процедури формування показника якості системи.

Очевидно, що по фізичному еству процес фрормування показника якості базуеться на принципі порівняння з деяким еталоном, для якого відомі або сформульовані на стадії зовнішнього проектування основні і оптимальні в певному значенні показники $Q_{0}=\left\langle Q_{01}, Q_{02}, \ldots, Q_{0 N}\right\rangle$. При оптимізації досягається мінімум відстані $\rho\left(Q_{1} Q_{2}\right)$ між кінцями $n$ - мерных векторів показників, визначуваних безліччю показників $Q_{0}$ еталонної і $Q_{1}$ проектованої системи

$$
\left.\operatorname{MIN} \rho\left(Q_{1} Q_{2}\right)=\operatorname{MIN} \sqrt{\alpha_{1}\left(Q_{1}-Q_{01}\right)^{2}+\ldots+\alpha_{N}\left(Q_{N}-Q_{0 N}\right)^{2}}\right)^{2},
$$

де $\alpha_{1} \alpha_{2} \ldots \alpha_{N}$ - вагові коефіціенти, вибирані так, що $\sum_{i=1}^{n} \alpha_{i}=1$.

Параметрична чутливість $S$ відстані $\rho\left(Q_{1} Q_{2}\right)$ до змін будь-кого $Q_{i} \in Q=\left\langle Q_{1}, Q_{2} \ldots Q_{n}\right\rangle, i=\overline{1, n}$ характеризуеться співвідношенням

$$
S_{Q_{1}}^{\rho}=\frac{Q_{1}}{\rho\left(Q_{1} Q_{0}\right)} \frac{d \rho\left(Q_{1} Q_{0}\right)}{d Q_{1}}=\alpha_{i} Q_{1}\left(Q_{1}-Q_{0}\right), i=\overline{1, n},
$$

3 якого виходить умова вибору найістотніших для заданого показника якості параметрів, що забезпечують $S_{Q_{1}}^{\rho}=M A X$.

Комплексний показник якості повинен відображати дозвіл головних і принципових для СОЕД компромісів: 
- між цінністю $V$ інформації і витратами $C$ на отримання даних (результатів вимірювання, контролю і т.д.) досягши однієї з основних метрологічних характеристик СОЕД - відносної погрішності $\delta$ (Рис. 1)

- між витратами $E$ на експлуатацію СОЕД і початковими витратами $P$ при зміні параметрів (наприклад, надійності $R$ ) системи (мал. 2). Звідси витікає, що показник якості адаптивної СОЕД повинен бути складовим і комплексним, тобто відображати техніко-економічні (витратні) аспекти всього життєвого циклу системи.

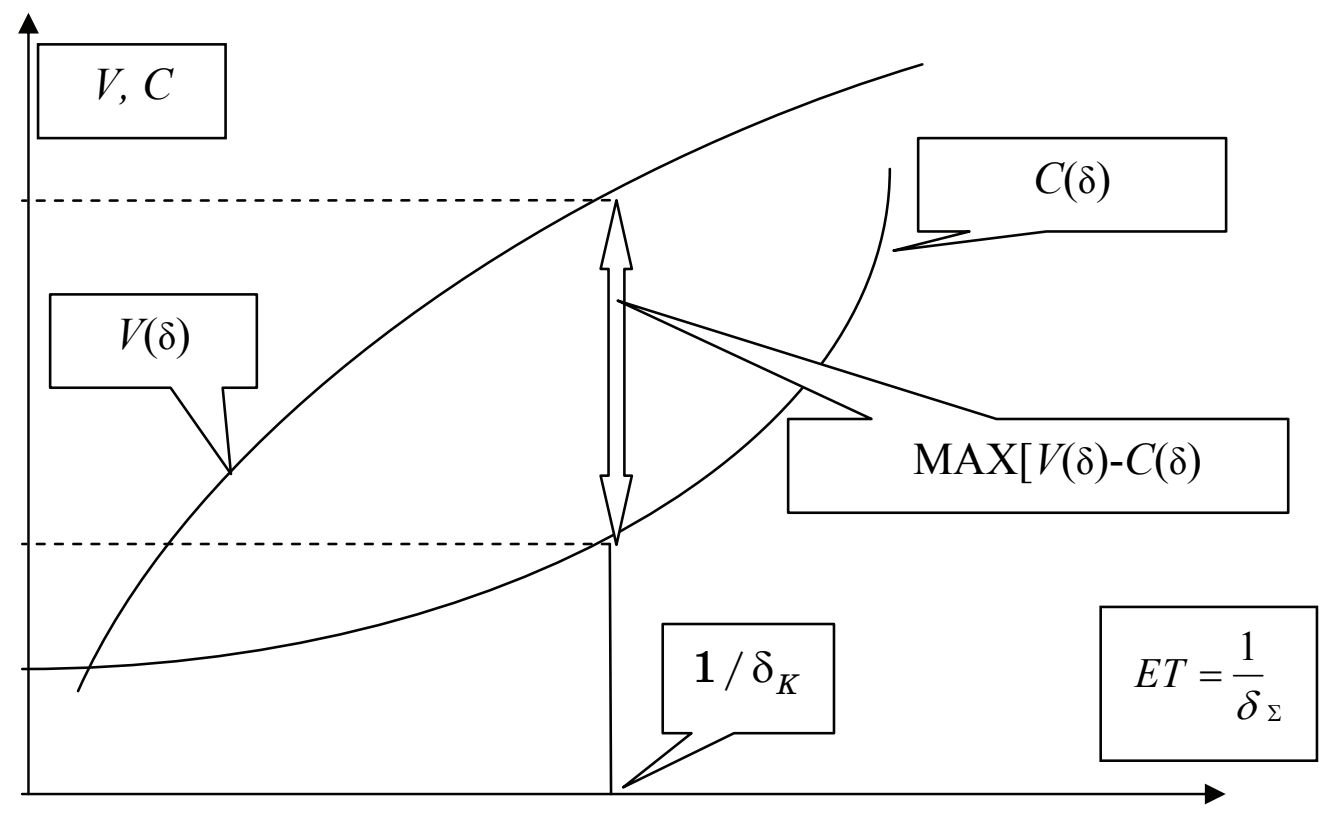

Рис. 1. Перший компроміс між витратами $C$ на отримання даних і цінністю $V$ інформації

Досягнення першого компромісу (рис. 1) припускає досягнення $M A X[V(\delta)-C(\delta)]$, а другого компромісу - досягнення мінімуму сумарних витрат ресурсів $F_{\Sigma}=M_{I N F_{\Sigma}}$ (Рис. 2). Різниця між $R_{\min }$ i $R_{\text {opt }}$ видна 3 побудов, приведених на рис. 2 .

Комплексний показник якості СОЕД або IBC може бути приведений в адитивній фермі при забезпеченні в процесі оптимізації наступних умов

$Q_{1}=\beta_{1} F_{1}+\beta_{2} F_{2}, M A X F_{1}=M A X[V(\delta)-C(\beta)], M A X F_{2}=M I N F_{\Sigma}$,

де $\beta_{1}+\beta_{2}=1-$ вагові коефіцієнти.

Спільність властивостей даного комплексного показника якості системи відображається єством поняття иінності $V$ інфорлацї $i$ витрат Ена ї̈ отрилання $і$ обробку.

Цінність інформації є основним критерієм для СОЕД і включає наступні чинники: погрішність (точність) вимірювання IBC у складі 
СОЕД, давність інформації про стан об'єкту (час отримання результатів і узгодженням їх з параметрами об'єкту), давність інформації для вироблення рішення (управляючої дії), можливість прогнозування (інакше кажучи, можливість проведення адаптації), доцільність і післядія.

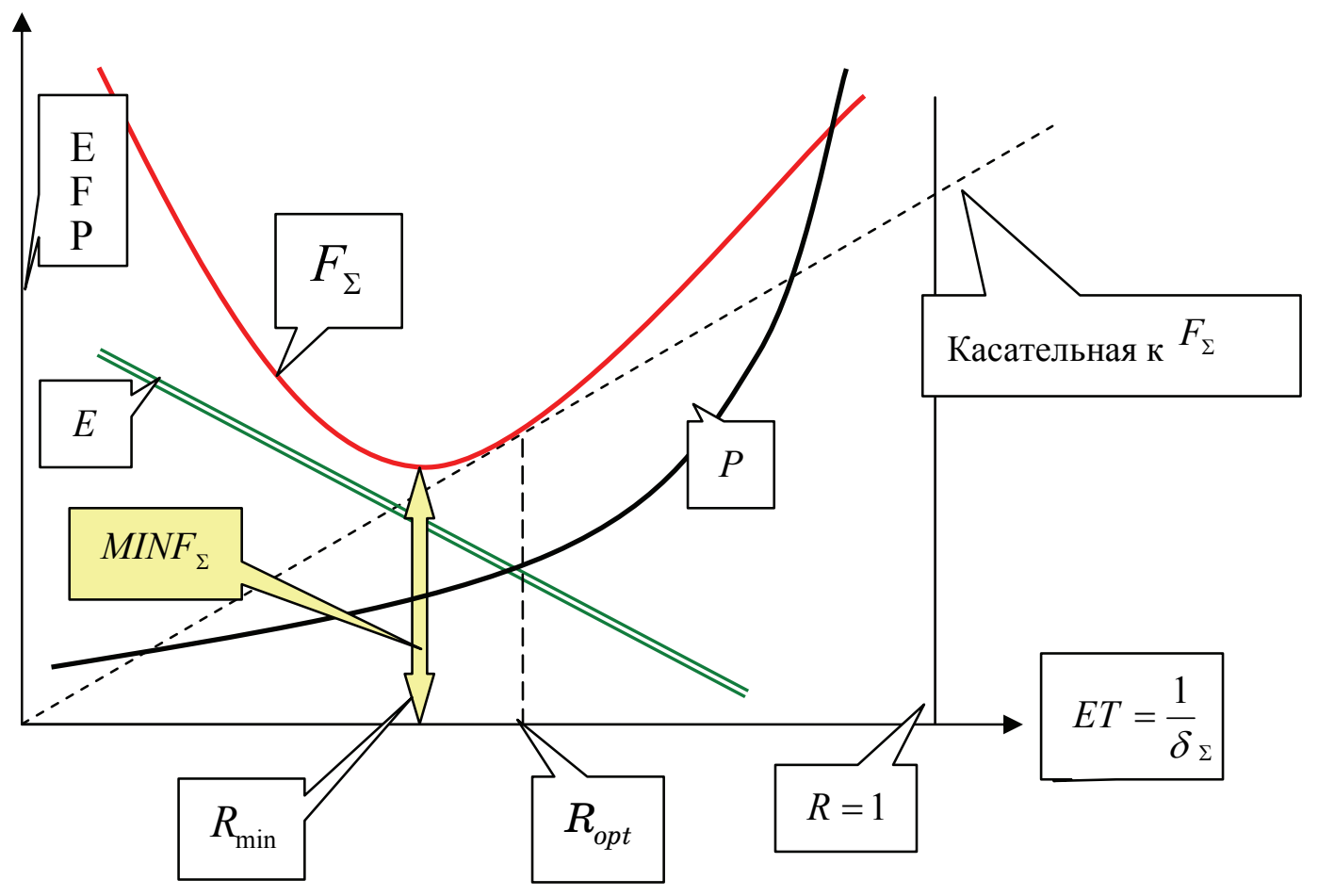

Рис. 2. Другий компроміс $F_{\Sigma}=M I N F_{\Sigma}$ сумарних витрат ресурсів

Проектування адаптивних СОЕД третього рівня самоорганізації в більшості випадків зводиться до проектування якоїсь дворівневої адаптивної СОЕД, в якій інваріантами є вже летакритерї (критерії більш високого рангу, наприклад, етичні або естетичні). Початковими даними в цих СОЕД є інформація про зовнішню обстановку і можливі внутрішні стани всієї безлічі проектованих СОЕД нижніх рівнів. До такого роду систем відносяться так звані “інтелектуальні” і деякі інші СОЕД, що спираються в своїй роботі на бази знань, що постійно обновляються, наприклад, активні (локаційні) і пасивні системи виявлення і класифікації, системи глобального позиціонування (GPS) та інші.

Відомо, що адаптивна СОЕД - це діалогова система, в якій діалог будується на аналізі інформації, отриманої в результаті рішення строго формалізованих задач на основі методів математичного моделювання. Для кожного класу проектованих систем змістовна сторона процедури опису (формалізації) має свою специфіку і у багатьох випадках, 
наприклад в медицині, унікальна. Ця теза дає підстави вважати, що неможливе створення універсальної адаптивної СОЕД, інваріантної до PRAR. Аналогічне положення i 3 розробкою експертних систем, оскільки доведено, що універсальні методи ефективні в обмежених випадках. Проте основні принципи, встановлені в основу побудови, як експертних систем, так і СОЕД різного призначення, швидше за все, єдині і можуть бути використаний при їх проектуванні.

Таким чином, будь-яка адаптивна технічна система повинна безперервно вирішувати оптимізаційні задачі, або, інакше кажучи, вирішувати задачі стохастичної екстраполяції (прогнозу) випадкових процесів. Методи статистичного прогнозу $\xi(t)$ дозволяють оцінювати майбутні значення за наслідками вимірювання минулих і поточних значень заданих характеристик вірогідності. До найточнішим, хоча і достатньо громіздким, способам прогнозування відносяться сучасні методи (в першу чергу імітаційного) моделювання на ЕОМ. Передбачені тим або іншим способом значення інформативних параметрів є початковими даними для $\xi(t)$ вироблення або управляючої дії, або для ухвалення рішення.

В системах автоматичного управління (САУ), наприклад, процес перетворення цих даних в управляючу дію складається з ряду математичних і логічних операцій, виконуваних аналоговими або цифровими процесорами. При цьому однією $з$ найважливіших задач $є$ розробка ефективних алгоритмів функціонування процесора при заданих (або вибраних) параметрах, наприклад, точності, швидкодії і т. д. Тобто завжди треба мати на увазі, що у складі будь-якої системи управління завжди є блок (вузол, пристрій) вимірювання сигналу розузгодження, що має структуру IBC.

\section{Висновки}

Розроблена класифікація адаптации для систем обробки експериментальних даних та інформаційно-вимірювальних систем може дозволити зменшити необгрунтовано завишенні вимоги до елементів систем і значно зменшити час і вартість їх розробки, що є перспективним напрямом в розробці адаптивних СОЕД і IBT.

Тому в адаптивної COEД, в яку інтегрована IBC (IBК) найдоцільнішою є зовнішньо-внутрішня адаптація, типовим прикладом якої є структурні методи підвищення точності, i, у меншій мірі, внутрішньо-внутрішня адаптація. 


\section{Література}

1. Пономаренко В. К., Мирошниченко В. С. Выбор параметров измерителей числовых характеристик случайных процессов, Известия ВУЗ СССР, разд. Радиоэлектроника, XVI, 1971, 7.

2. Туз Ю. М. Структурні методи підвищення точності вимірювальних пристроїв. - К.: Віща школа, 1976 - 256 с.

3. Зинченко В. П. Показатели качества базового программного обеспечения, методы их измерения и оценки // Интеллектуальные информационно-аналитичесие системы и комплексы. - К.: НАН України Ін-т кібернетики ім. В.М. Глушкова, Наук. рада по проблемі "Кібернетика", 2000. - С. 142 - 161.

4. Кетков Ю., Кетков А., Шульи М. МАТLAВ 6.х. Программирование численных методов. - СПб: ”БХВ-Петербург”, 2004-1080 с. 